\begin{tabular}{ccc}
\hline & International Journal of Engineering \& Technology, $7(2.20)(2018) 214-218$ \\
SPC & International Journal of Engineering \& Technology \\
Website www.sciencepubco.com/index.php/IJET & Research paper \\
\hline
\end{tabular}

\title{
Geometrical behavior of laminated graphite/epoxy composite using hypermesh
}

\author{
Ch. Siva RamaKrishna *, KV SubbaRao, Saineelkamal Arji \\ Vignan's Institute of Information Technology, Visakhapatnam, Andhra Pradesh, India-530049 \\ *Email: srkchadaram@gmail.com
}

\begin{abstract}
The laminated composite material is made of ply which are specically used in automotive, aerospace and military applications due to less in weight and high strength to weight ratio. The role of structural strength is very important in composites, as the material is weak in inherent strength leads to damage of equipment made with the laminated composite. Hence, an accurate understanding of their structural geometrical behavior for residual stresses is required, such as residual stresses with different aspect ratios. In present work, various aspect ratios of laminated composite and its residual stresses are investigated using finite element analysis. The numerical results showed, on the residual stresses, that the effects the change the residual stresses due change of aspect ratio of laminated Graphite/epoxy composite.
\end{abstract}

Keywords — Laminated composite plate, Graphite/Epoxy, Residual stresses, Geometrical behavior, uniformly distributed load, hyper mesh

\section{Introduction}

Laminated Composite material is formed by joining of number of layers made of polymer based materials to get desired mechanical properties like high strength to weight ratio, stiffness, low deflections, stresses etc., The composite material concept is applied to polymer materials, metallic and ceramic matrix materials. In case of composite materials , the fibers are used include boron, glass, silicon carbide, graphite, cellulose, and other matrix materials are alumina, titanium, polymides, epoxies and aluminium. The aspect ratio is the ratio of length to width of laminated composite plate which in turn develops the geometrical behavior of the composite.

\section{Literature Review}

Moon Chang-Kwon[1] studied the composite laminate materials are an alternative design solution in terms of specific strength and stiffness. For a particular application, designer is provided with required freedom to design interns of the strength and stiffness optimization of a component or structure .R.C. Novak and M.A. DeCrescent [2] The individual layers thermal and mechanical properties in crossed-plied composite made of graphite and epoxy are greatly influences on residual thermal stresses are present in the composite. Analytical method and experimental method of evaluation in different cross-ply composite for residual stresses is done and compared the results for validation. The transverse tensile strength is of the unidirectional composite is considered for investigations on cracks and its occurances are clearly presented. by consideration of stresses developed. Stango R.J. and Wang S.S [3] presented $\mathrm{n}$ advanced fiber-reinforced composite laminates with consideration of in-process stresses are presented. [4,5,6] papers will help to cover extensive knowledge on layered composite plates. An analysis with quasi -three dimensional FE method is used for the residual thermal stresses of laminate. Using hyper mesh is identified as knowledge gap to estimate the strength of laminated Graphite/Epoxy composite.

\section{Methodology}

Hyper mesh has high strength in modelling of complex problems with accurate results as it consists of leading premier preprocessor. The Hyper mesh helps in not only the complex geometry it can solve the problem with faster. The other capabilities are meshing and the advanced geometry environment. The core competencies are high quality mesh and fast process. As a part of work hyper mesh is used to estimate the residual stresses with below procedure

Step 1: Open window HYPERMESH

Step 2: Material creation

Choose the materials by using menu bar File Edit View collectors Geometry Mesh connectors Materials Properties BCs Setup

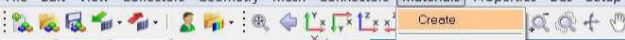
Utility [ Mask | Model

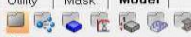

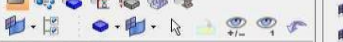
Entities ID

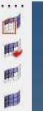
\begin{tabular}{l} 
Organize \\
Renumber \\
\hline
\end{tabular} Hypertaninate

Enter the fields enter Graphite-Epoxy

$>$ Enter the values of E1 as 181e3.

$>$ Enter the value of E2 as $10.36 \mathrm{e} 3$.

Step 3: property creation

Access the Create property from the menu bar

$>$ Click Close

Step 4: Create a component to hold the model's geometry. 
Access the Create component window

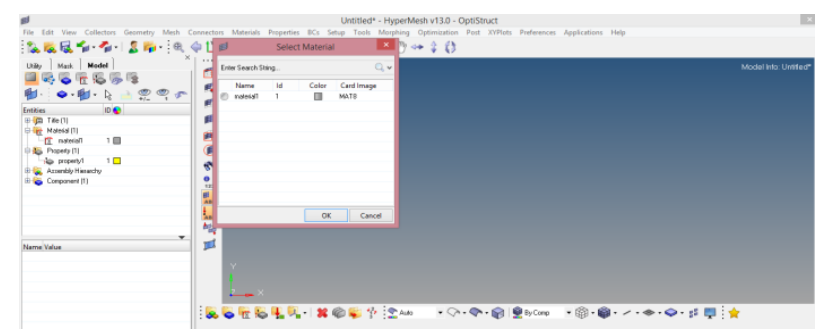

Step 5: Create nodes

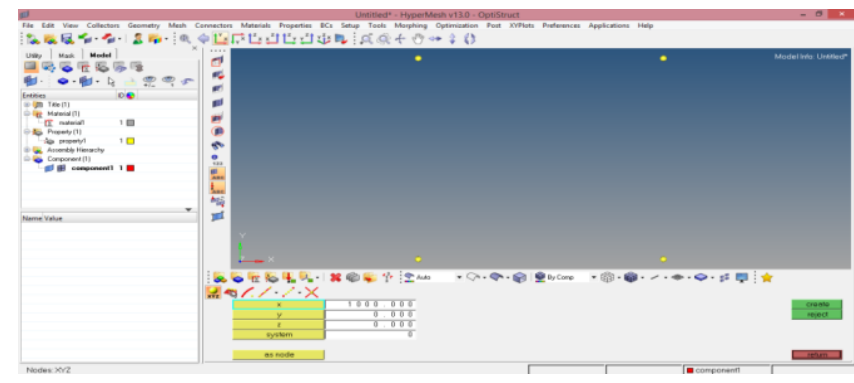

Step 6: Display the node numbers.

For node numbers use the menu bar, choose Geometry > Check > Nodes $>$ Numbers.

Step 7: Create straight line

Access the Linear Nodes panel

With node list selected, click on node $1(0,0,0)$ and node $2(1,0$,

$0)$;Click create.

B his will create a line going from node 1 to node 2 .

Repeat this process to create straight lines using the following nodes:

$2 \& 3,3 \& 4$ and $4 \& 1$

Step 8: Meshing

Go to 2D

Select two opposite lines and click on one line then click create and click on opposite line and again click on create

Give the element size $=50.0$

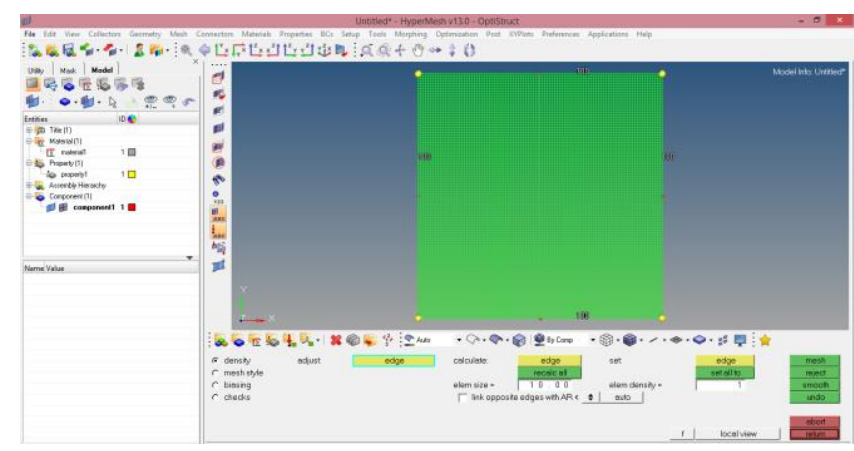

Step 9: Creating ply

$>$ Access the Create Ply window form the menubar, choose Properties $>$ Create $>$ Plies.

$>$ Set the Material type to ORTHOTROPIC.

$>$ Set the thickness, enter : 0.00015

$>$ Set the Orientation, enter: 0

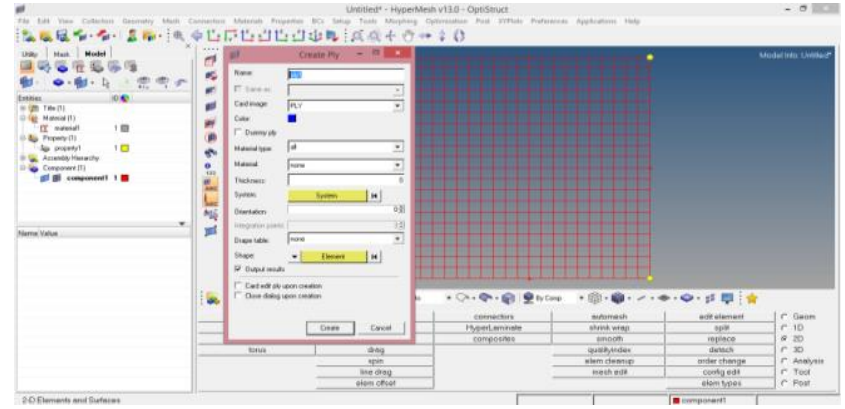

$>$ Repeat this process to create three more plies (PLY2 and PLY3,).

Step 10: Create a Ply Laminate

Access the Create Laminate window using menu bar, by choose Properties > Create > Laminates

Step 11: Create a Load Collector

$>$ Access the Create Load Collector window using the menu bar, choose Collectors > Create > Load Collectors

Step 12: Apply Constraints

Click on analysis for analysis and go to constraints, to create nodes on the element, then click on node, select by window, after select which area is want to constraint.

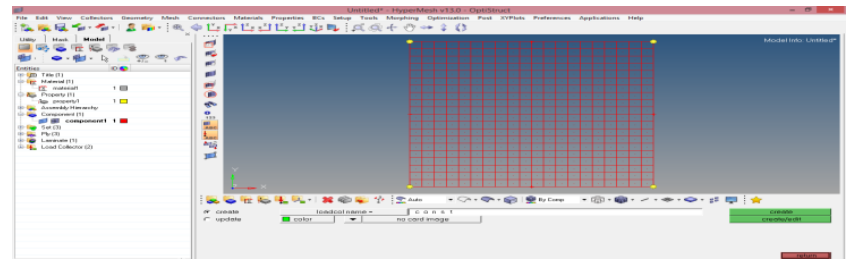

$>$ Click on select entities

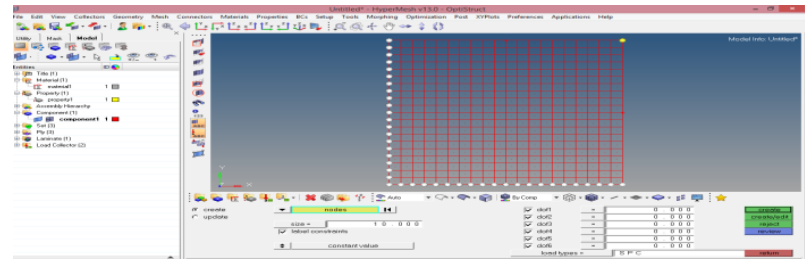

$>$ click on create

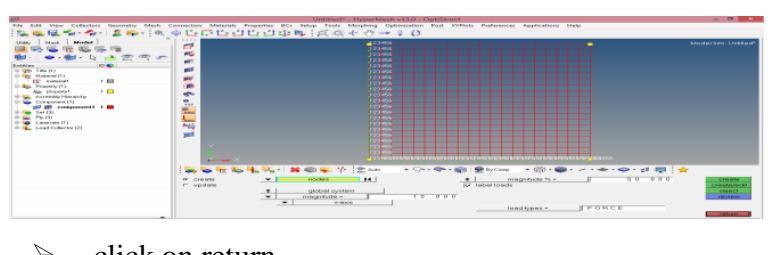

$>$ click on return

Step 13: Apply Temperature

$>$ In analysis click on temperature.

$>$ In temperature click on create and double click on nodes, select displayed

$>$ Click on proceed.

$>$ Give the value is $-75^{\circ}$.

$>$ Click on create. 


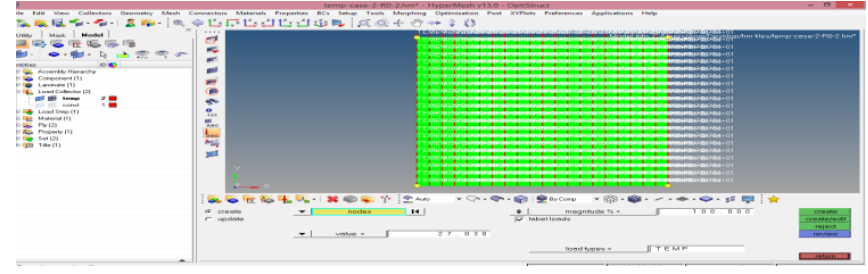

$>$ Click on return.

Step 14: Load Steps

$>$ In analysis click on load steps.

$>$ Give $\mathrm{SPC}=$ constraint and $\mathrm{TEMP}=$ temperature.

$>$ Click on create.

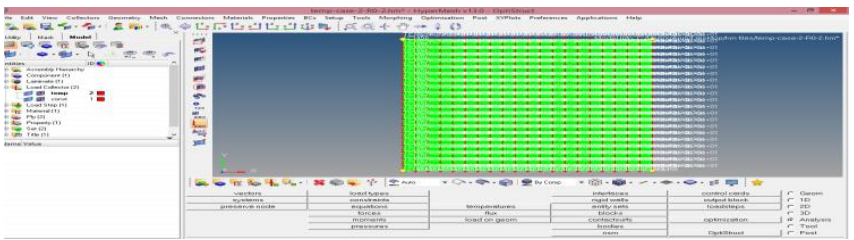

Step 15: Optistruct

1. In analysis click on optistruct.

2. The solution is running, after completion of solution go for results.

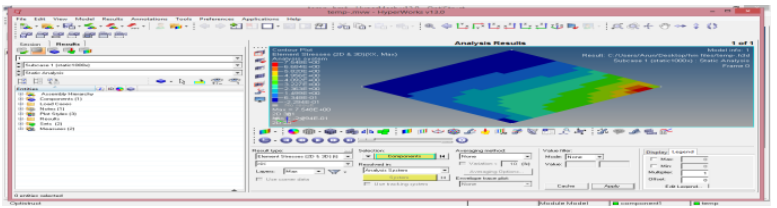

3. In results type give the $\mathrm{x}$-direction and click on apply.

\section{Results and Discussions}

When aspect ratios is 1, 2, 3, 4 and 5 the residual stresses are developed as shown in Fig.1 to 15. The figures are shows the output values at different aspect ratios and stresses in $\mathrm{X}, \mathrm{Y}$ and $\mathrm{XY}$ directions.

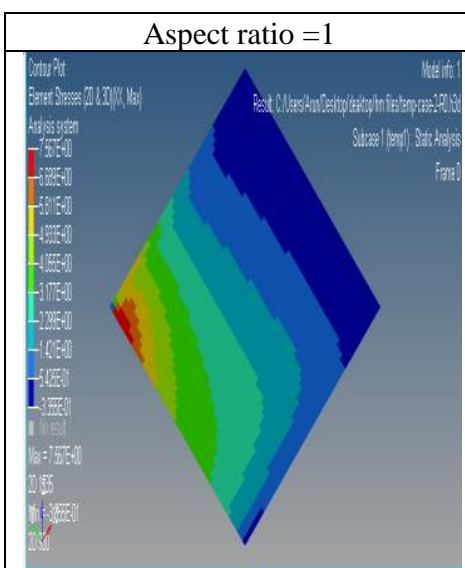

Fig.1.Residual Stress in X Direction

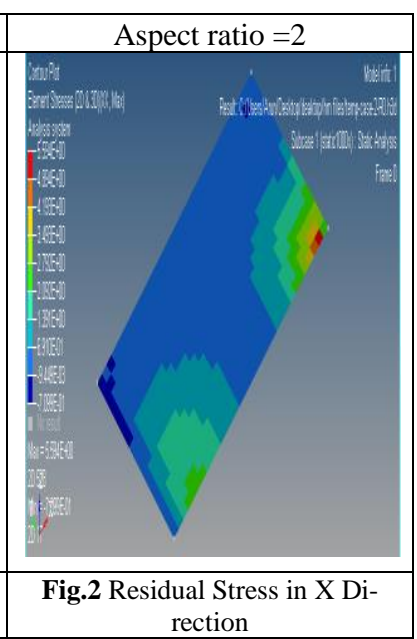

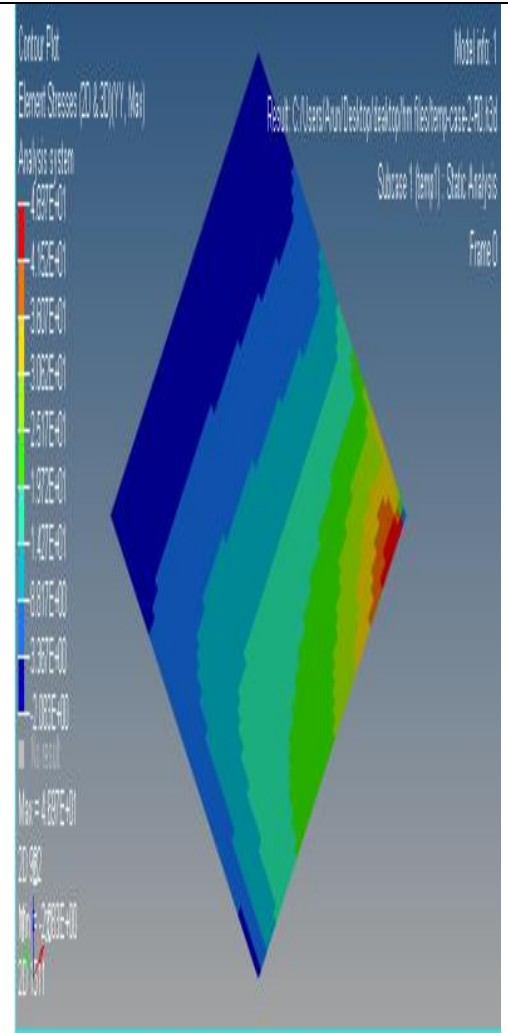

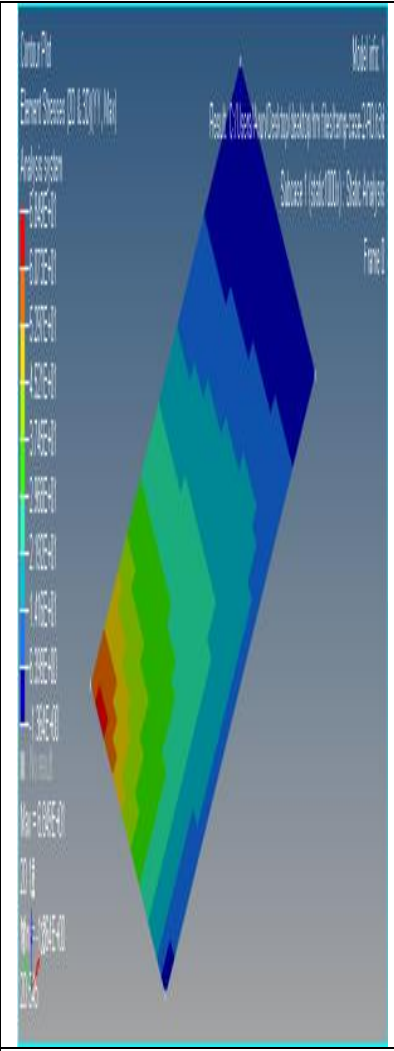

Fig.3 Residual Stress in Y Direction

Fig.4 Residual Stress in Y Direction

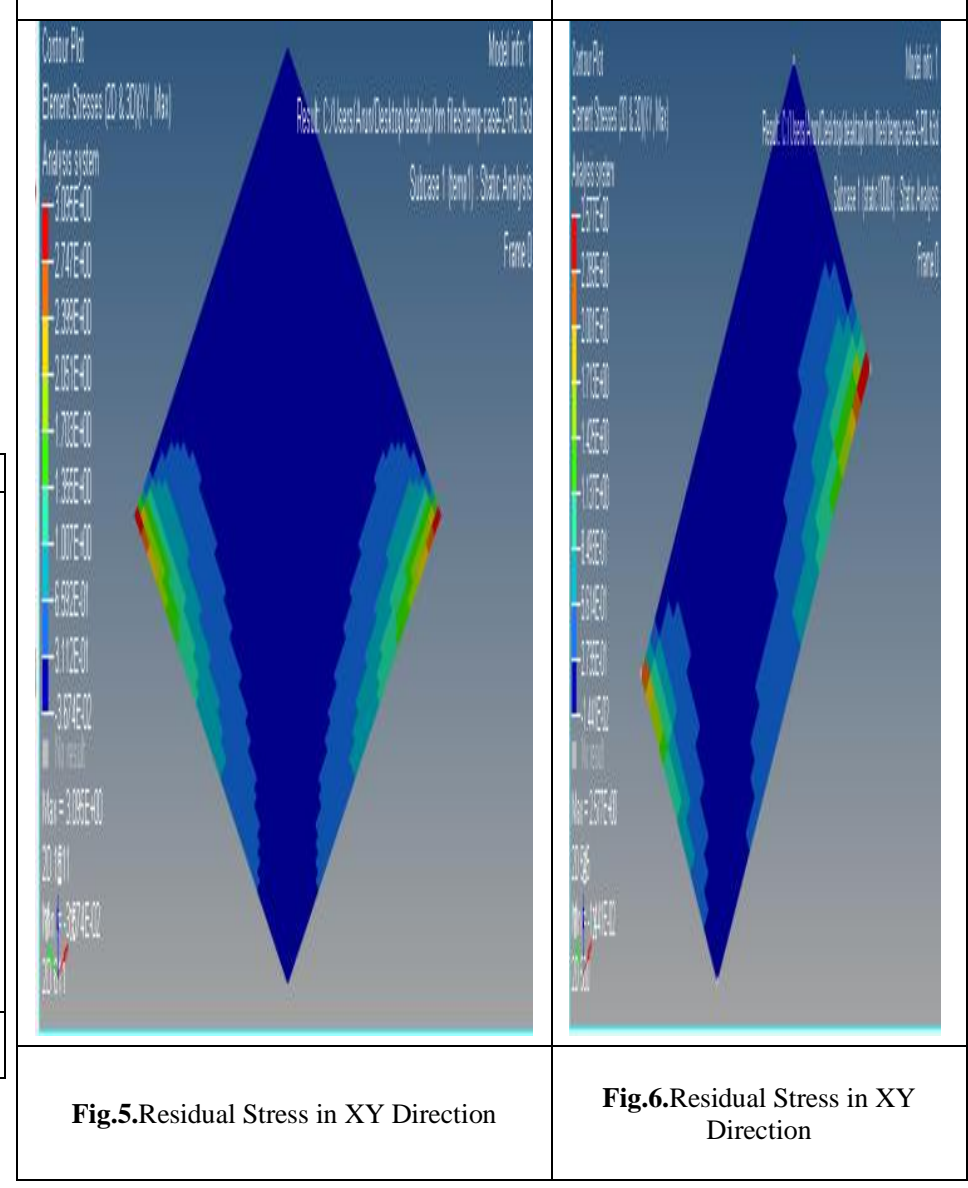




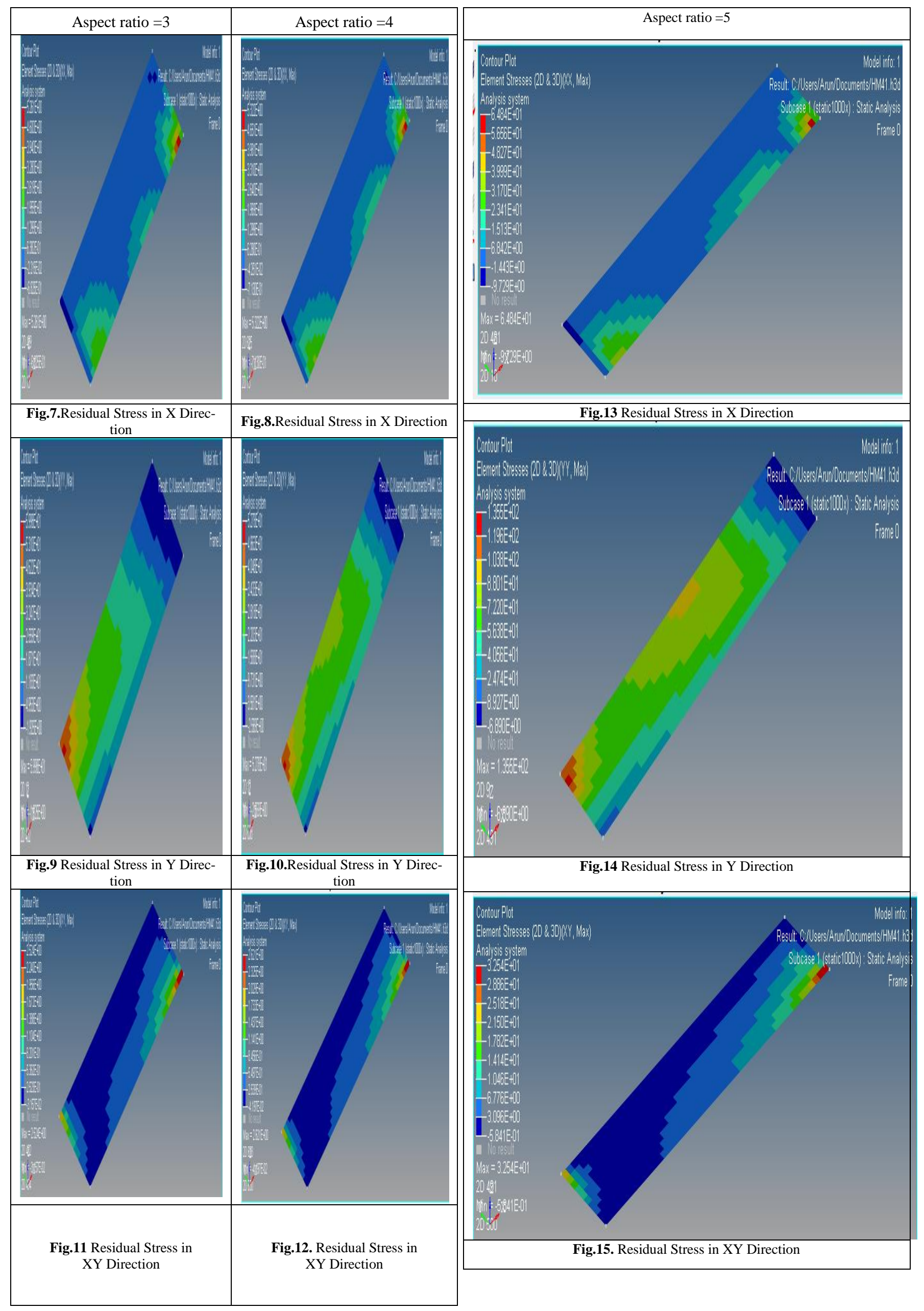




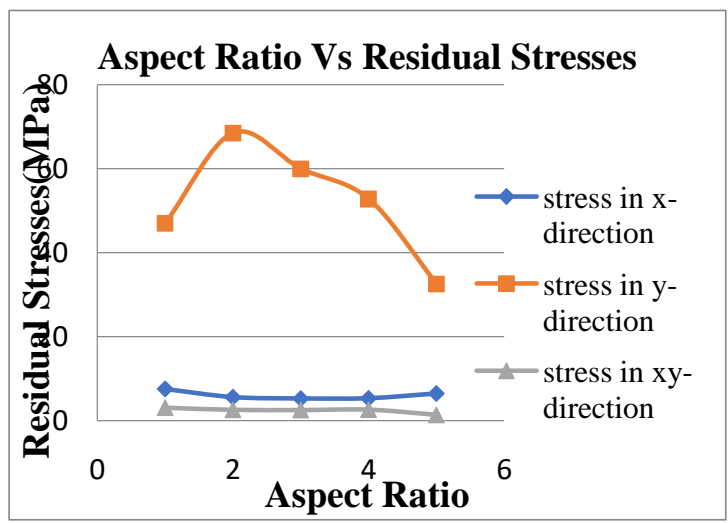

Graph.1 Aspect Ratio Vs Residual Stresses

From the graph, when aspect ratio changes, the residual stresses in $\mathrm{X}, \mathrm{Y}$ and $\mathrm{XY}$ directions. The stresses in $\mathrm{Y}$ direction is more compared to $\mathrm{X}$ and $\mathrm{XY}$ directions

\section{Conclusion and future scope of work}

The laminated composite residual stresses are successfully developed using Hypermesh. when aspect ratio changes the change in residual stresses is identified. The stress in xy-direction get lesser value as compared with other directions. As the aspect ratio value increases, the residual stresses values may get decreased simultaneously after attaining a maximum position as in Y direction.

\section{References}

[1] Moon Chang-Kwon. The effect of interfacial microstructure on the interfacial strength of glass fiber/polypropylene resin composites, Journal of applied polymer science, 54(1), 1994, 73-82.

[2] R.C.Novak and M.A. DeCrescente, Fabrication Stresses in Graphite Resin Composites, J. Engineering for Power, Vol. 92 (1970), p. 377

[3] Stango R.J. and Wang S.S. Process induced residual stresses in advanced fiber-reinforced composite laminates, ASME J. of Engineering for Industry, 106(1) (1984) 48-54.

[4] R.Sahoo and B.N. Singh, A new trigonometric zigzag theory for static analysis of laminated composite and sandwich plates, Aerospace science and technology, vol.35, pp.15-28, 2014.

[5] M.H.Rarani, S.S.K.Sharifi and M.M.Shokrieh, „Effect of ply stacking sequence on buckling behavior of E-glass/epoxy laminated composites, Computational Material Science, vol.89, pp.89-96, 2014.

[6] K.Alnefaie, Finite Element Modeling of composite plates with internal delamination, Composite Structures, Vol. 90, pp 21-27, 2009. 